off as by magic. If mountain sickness can be prevented by training for the exercise of climbing ander low pressure, why should not asthma also yield to the training of the respiration carried out by practising the respiratory movements wanted to carry the tidal air through the lungs to oxidise the blood and emit the carbonic acid, while imparting to the circulation a better tendency to work in perfect barmony with the respiratory requirements? of all means of training the respiration 1 think cycling is the best. When a person first takes to cycling he is troubled with shortness of breath, his heart beats uncomfortably, and his legs get tired, but after some training these discomforts all disappear. Why should not people liable to attacks of asthma also train their respiration by such a kind of exerciseof couree, on condition of the heart and lungs being in perfect health? Cycling exercise first of all increases the depth of breathing, and that without fatigue, as the respiratory movements are automatic; at the same time it will accuetom the rider instinctively to take in at each respiration the volume of air required to aerate the blood and to eliminate a fixed proportion of carbonic acid, leaving in the circulation the precise amount compatible with health. In cycling volition has also a good deal to do towards exercising the motor centres to take in the exact volume of oxygen required for that kind of work. Persons who do not care for cycling out of doors can take the same description of exercise at home by means of a dammy cycle. Mg experience of the results of this treatment is anfortunately only limited to one person; in which case it has proved eminently successful. This person took to bicycle riding three years ago, first for pleasure and then on account of his health. He observed last summer that attacks of asthma to which he was subject had become very mach fewer, having only suffered two since last October, both of these being brought on by exposure to cold. The tightness and wheezing which occurred every night have mearly entirely disappeared; his sleep, which for years had been restless and broken, has very much improved; and al this he ascribes in a great measure to the use of the bicycle.

Allow me, Grintlemen, to summarise shortly the Croonian Lectures for the present year. In the first lecture the oxygen of the atmosphere was shown to be the main agent of life, and Hermann's discovery that oxygen is an integral part of the tissues was appealed to with the object of explaining the remarkable tenacity of life of certain organisms-such as seeds. Next came an attempt to explain that it is not the oxygen of the air which, by offering itself to the tissues, produces the phenomena of metabolism, but that the living tissues call upon the oxygen to effect the changes they undergo. The influence of tissues as the pime movers in the matter was shown by the action of cold, which, through the nervons system, first increases their vitality and conseqnently their demand for oxygen, though when the cold is excessive it exerts an influence the reverse in its character. Muscular exerciae invariably tends to the production of carbonic acid in excess; and this led to soma remarks on the temperature of the body while in the act of ascending. It was concluded that with some people there is a slight increase and with others a slight fall of temperature. The second lecture was prefaced with a short allusion to past investigations on human respiration; then followed the history of the different forms of breathing, which were illustrated by tracings (reduced in siz $)$ taken directly from the person under experiment. Attention was also drawn to the interesting phenomena of the absorption of oxygen in the body independently of the formation of carbonic acid, and a number of analyses were quoted showing to what extent this absorption takes piace. The third lecture was given up entirely to the influence of volition on the respiration. It was shown that volition towards any kind of muscular exercise, including forced breathing, is atrended with the absorption of oxygen in excess, and that this oxygen is necessary towards the performance of volition, and, if necessary to volition, it must be taken ap by the motor centres of volition. A remarkable effect on the development of muscalar force by this charging of the motor centres with ozygen was shown to take place. Finally, an experiment was deseribed in which, volition becoming tired out, the muscles refused to work, this experiment being in keeping with Mosso's discovery. The fourth lecture was devoted first of all to an account of the inflaence of climbing on the respiratory changes and on the state of the respiratory phenomena at high altitades. Next, rebreathing and air oreathed under pressure were considered, and it was explained that the effect of rebreathed air was apparently due more to the want of oxygen than the absorption of carbonic acid. After a few remarks on the effects of breathing mixtures of carbonic acid and common air the lecture was concluded with an allusion to asthma and a method of treatment suggested by the considerations which may be looked upon as the substance of these four lectures.

\section{THE VARIETIES OF RHEUMATOID ARTHRITIS.}

BY R. FORTESCUE FOX, M.D. LOND.

THuRe is no class of affections for which relief is more commonly and, I may add, more justly sought at mineral waters and baths than painful enlargements of the joints, particularly those to which the adjectives gouty, rhenmatic, or rheumatoid have been attached. It is the object of this paper to present some typical examples of the complex group commonly known as rheumatoid or osteo-arthritis out of a considerable number that have come under my observation at Strathpeffer $S$ pa, to describe by their aid the several varieties of disease at present united under that name, and to deduce if possible some conclusions as to their actual nature. The material at our disposal is clinical-postmortem examinations are happily rare-and no light has, so far, been shed upon the subject by the method of experiment. CASE 1.-A young woman aged twenty-four years was placed under my care in September, 1888, by Dr. Chalmers of Stirling, with the following history. There was no known tendency to rbeumatism or other illness in the family. The patient had been quite well until eighteen years of age, when in the spring of the year "rheumatism" began quite quietly to show itself in the feet and hands, but without fever or confinement to bed. The catamenia had commenced late-at seventeen-only six months before the onset of the joint troubles; these had been always irregular, two, three, or four times only in the year, and it was stated that the pain, swelling, and stiffness of the joints had been usually worse for a week or more before the periods. In the six years that had elapsed before coming to the $\mathrm{Spa}$ the patient had resided in an exposed situation near the east crast of Scotland, and the affection had gradually involved not only the feet, hands, and wrists, but, latterly, the knees and eloows also. In September, 1838, she was obviously much out of health, there being frequent neuralgic headache, malaise, anorexia, profuse perspiration, sometimes confined to the back of the neck and head and to the hands, which were cold. clammy, and sodden with moisture. The pulse was 90 and the beart was normal. Severe pains were present in the joints and in the body generally; these were always worse at night. A course of baths considerably relieved the symptoms, and she remained much better for three months, when the complaint returned and gradually incapacitated her, although, with great energy, she continued her occupation as teacher in a bleak country-side, and was carried to and from the schoolhouse in the winter months. This was followed by a long period of confinement to bed, with cod-liver oil treatment, and considerable improvement in general health resulted. In the following February (1890) she returned to Strathpeffer, presenting the following condition. The hands still had a white, sodden, odematous appearance; the finger joints, formerly so much swollen, were nearly natural in size, but two or three were slightly stiff; the wiists were uniformly swollen and nearly immovable; the elbow-joints were both swollen and stiff, the left being almost immovable; the feet were swollen and painful; atd the knees, hips, and shoulders were practically unaffected. In July of the same year, the joints being quiet and the general health much improved under a prolong ad course of Spa traatment, I broke down the adhesions in the stiff elbow under an anæsthetic In February, 1895, thirteen years after the onset of the malady, this patient wrote that sbe was confined to her couch or bath-chair; both lezs and the right arm were stiff from adbesions and were useless, but the arm on which the 
operation was performed five years ago remains a fairly movable and usef ul limb.

CASE 2.-A girl, a gamekeeper's daughter, had enjoyed good health until eleven years of age. No tendency to hereditary disease had been noted, excepting that her father, like most gamekeepers, had had rheumatism slightly. At that age she had influenza, with severe pains in the limbs and a skin eruption. Four months later, while going about daring the snmmer of 1890, rhenmatoid arthritis gradually set in, affecting, successively, the left hip and thigh, both hands, and the left foot. A year later (June, 1891) she sought relief at Strathpeffer, and her condition was then as follows. The patient was twelve years of age, tall, delicate, weak, anæmic, and subject to profuse perspiration. She bad been growing quickly. The catamenia had not appeared. The right wrist was uniformly and evenly enlarged, painful and tender, with very limited flexion movement; the left wrist was similarly affected, but less so. There was in both wrists slight crackling on movement. The left ankle was slightly enlarged and tender. She remained for two months under Spa treatment, taking a course of douche baths in addition to sulphur waters internally; she left greatly benefited. In August, 1891, she returned; there were wasting of the interossei muscles and too great prominence of the styloid process of the ulna, the wrist remaining nearly stiff, but the inflammatory stage being confined to the middle joint of one firger. Three and a half years later (March, 1895) she wrote that she was quite well, but the right wrist remained stiff and swollen, and the one finger still affected.

These two cases illustrate the rheumatoid arthritis of young subjects, and it is, in my experience, in the young that the disease assumes its most severe and intractable, and, I would, add, typical, form. (See Figs. 1,2, and 3) A large number of joints are ufually

Frs. 1.

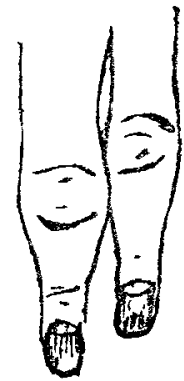

Third and fourth fingers of ight band of female aged thirteen; two years after onset of arthritis.

Fun.?

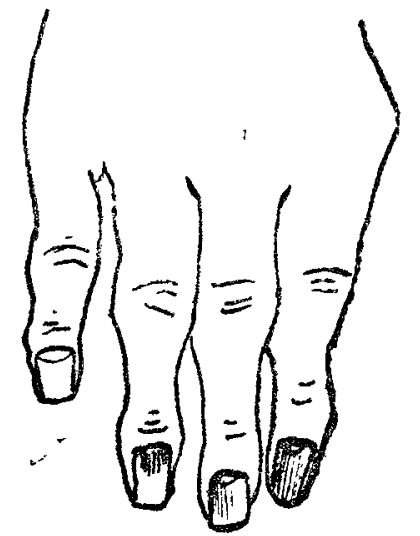

The same three years later commencing affetion of terminal joints.
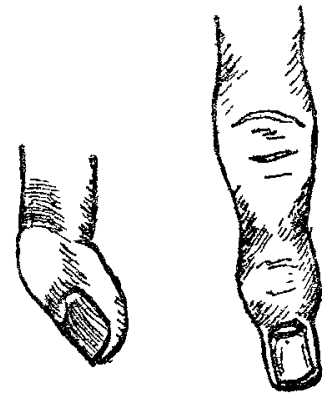

The same, third right finger; first lef finger (latera view); soft rounded dorsal swellings.

affected, and there are, from the first, profound debility, rapid beart, profuse perspiration, and progressive wastirg. The articular symptoms vary according to the severity and duration of the malady. During the inflammatory stage, which commonly extends over several years, there is always swelling, usually (though not always) symmetrical and involving both the joints and the extra-articular structures. In the acute condition there are synovial effusion. heat, and extreme pain and tenderness. Mobility rapidly diminishes, and stiffness may ensue early in the case. Pain is pre sent always and is referred not only to the joint but to the nerves and muscles. In the joint it is duil aching, or burning in character when at rest; severe and acate on movement; and it is darting and lancinating when referred to the nerves. Neither season nor weather commonly affect the pains. In some cases it is specially noted that they are more severe in the hot days of summer in others, especially in the early stages of the complaint, that the pains tend to subside in summer and retarn in winter. Increased stiffness is frequently complained of during a change in the weather, and it is usual for the pain to be more severe in the night-time, particularly from 3 to 5 A.X. The second period of the disease is marked by degeneration and atrophy both of joints and museles. Certain joints are subject to occasional returns of inflammation, bat the main condition now is one of atrophy, with stiffness and more on less-sometimes very little-deformity. Such deformity as exists is due to muscular wasting and subluxation of the phalanges rather than to lipping of the articular edges or osteophytic growths, which are rarely met with in rhen. matoid arthritis of the young. The middle phalangea joints, the wrists, and the tarsal joints seem to be particularly obnoxious to the disease, and are usually much swollen. Somewhat later in the disease one commonly finds several of the terminal phalangeal joints absolutely stiff anc obviously atrophied. The joint is thinned and concave on the dorsal aspect, and covered by glossy skin, and yet $I$ have seldom met with swelling or inflammation of these joints in rheumatoid arthritis; the fact of their becoming affected with simple atrophy is not without a bearing on the pathology of the disease. (See Fig. 4.)

Rheumatoid arthritis of the young is, in my opinion, a clearly outlined clinical variety of the disease. Out of forty cases of which I have fall notes thirty-two are females-that is, four out of five; and of the eight males two should perhaps be excluded as gonorrbca preceded the arthritis. Tho youngest of my cases was six years of ageat the commencement of the disease. The average age is twenty-two years and a half; this is the age of catarrhal affections and of tubercle not the age of adolescence or development, but the age at which the finished nervous and bodily powers are pat to theil first serious practical strain. It is also, therefore, especially in the female sex, the time of nerrous and emotional tension and breakdown. In some cases (thirteen or fourteen out oi forty) depressing jllness preceded the arthritis, such as typhoid fever, great nervousness and weakness, infinenza suppurative otitis, double conjunctivitis, abscess of the righ hand repeatedly lanced (in this case the disease $b \in g a n$ in the right thumb). dyspepsia and chronic diarrbæa, dyspepsia when at school in Germany, and exhaustion afte childbirth. The exciting cause is stated in a good many (twelve) cases to be chill or cold, sitting on damp grass, Sc., and in one case the shock of a railway accident. Certain localities, or rather climates, are favourable to the development of the disease, and eight of the forty cases came from the east coast or near the east coast of Scotland, particularly about the Firth of Tay. The following symptoms are noted as preliminary or pre-arthritic and have some bearing on the nature of the disease: pecnlias "want of animal heat" and a "zense of chilliness" (this was noted as continuing in one case for three years, and in another for some years, before the joints became affected, after which there was natural warmth; Sir slfred Garroc has noted "languid circulation and cold extremities" as common in rheumatoid arthritis, but this common condition is not, I think, usually associated with the sensation of cold); pains under the balls of the toes and, as my friend Dr. Spender of Bath bas noticed, pain at the root of the thumb. toothache-like pains in various joints-worse at night; numbness and aching in the fingers; heat and pain in the soles of the feet (a frequent observation); pains all over the body flying pains, languor and sense of fatigue (several sases); pain, sweating, and restlessness; and pain and stiffness in the calves of the legs accompanied by dark blotches on the thighs. These are the symptoms recorded as existing for 2 variable time before the localisation of pain and swelling in the joints. Dr. Spender has dwelt upon the importance of recognising these early symptoms; and $I$ have myself seen several cases in young people in whom the rapid pulse, localised sweating, nenralgic pains, and peculiar debility presaged, only too surely, the onset of this frightful malady The following cases are typical of a somewhat similar condition met:"with later in life. (Eee Figs, 4 and 5.) 
CASE 3.-A tall, robust, vigorous, married woman fiftythree years of age had suffered from no particular illnesses. Both parents were healthy and died when over eighty years of age. One brother died from phthisis, and a sister had had sciatica and muscular rheumatism. The patient was childless; a fibroid of the uterus had been discovered at forty, bat had not inconvenienced her much, and the catamenia ceased naturally at forty-nine, since which time (four years) she had been subject to heats and flushes with occasional pains and swellings in the knees. At fiftythree years of age she contracted a chill when heated, and was laid up with severe pain in the left hip and wrist and to a lesser extent in the right ankle. The painfal parts became swollen and she perspired profusely. Seven months later (October, 1892) she came for treatment to Strathpeffer. Both the knees were at this time greatly enlarged, in addition to the left wrist and right ankle. Although she was scarcely

FIG. 4.

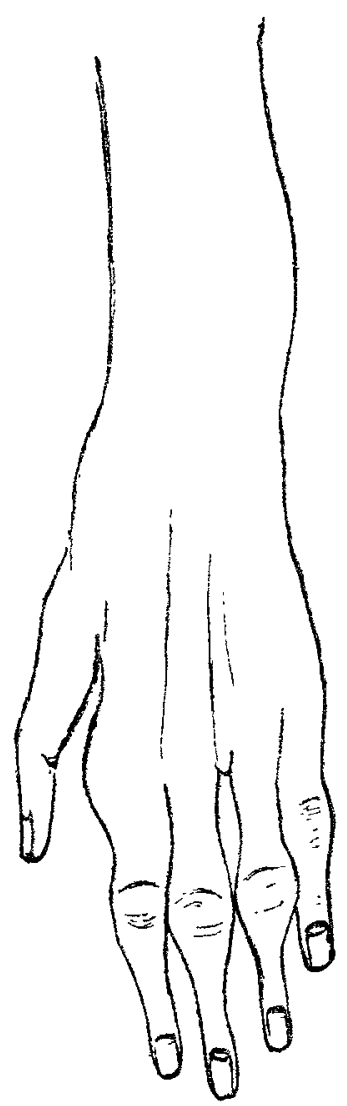

Fia. 5.

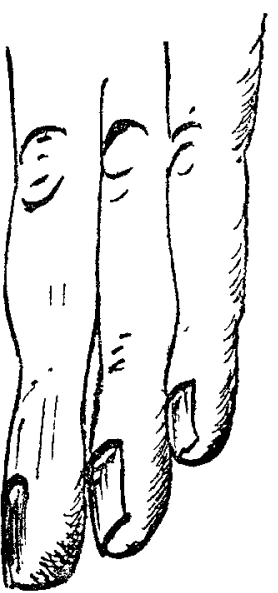

Third, luurth, and fifth fingers of female aged fifty-four ; eight months after onset of arthritis. Terminal joints stiff and atrophied, joints stiff glossy on the dorsal nally ridged and brown.

Left hand of female aged twentyfive; two rears after onset of arthritis.

able to walk a course of warm douche baths were successfully given. In the following Jaly she retarned, reporting considerable improvement, but the knees still remained painful, and, indeed, rather more swollen, and there was much crackling on movement. Some of the terminal phalangeal joints, not obviously affected before, were becoming atrophied, with stiffness and glossy skin. (See Fig. 5) A full course of douche baths was ordered, in addition to sulphur waters internally, and in the following winter she took, by my advice, a long course of arsenious acid with carbonate of iron. In Jane, 1894, she made a third visit to the Spa, reporting herself as much better and walking two miles. She was free from pain, excepting on damp days; the left wrist was almost absolutely stiff; there was dry crackling in the left thamb, and some of the fingers did not close properly. After further hot douching and massage a limited movement was obtained in the left wrist, and since then she had remained, but for the stiff joints, practically well.

CASE 4.-A married woman aged forty-two came to S rathpeffer in June, 1888, having suffered from rheumatoid arthritis about twelve months. The family history showed no signs of rheumatism or gout, but one sister had died from phthisis at twenty-four. The patient, who had never had rheumatism before, was the mother of nine children, and the youngest, born when she was thirty-nine, she had nursed for fifteen months. The arthritis, for which no canse is assigned, came on in June, 1887, "simultaneously in all the joints," and confined her to bed or couch for nearly twelve months. On arrival at Strathpeffer the knees and hands principally were found to be affected, the former being very stiff, painful, and swollen, and the mid-phalangeal joints were becoming stiff and concave on the dorsal aspect. The general health was low, she being subject to frequent perspiration, especially of the hands, and acute pains. Although confined to the hones and almost to bed, a course of waters was taken in 1888 and in the following year, on both occasions with benefit. Two years later (JuJy, 1891) she returned, four years after the onset of the disease, presenting the following condition. The right hip-joint bad been acutely affected, and was still much swollen and excerdingly painful on adduction and abduction. The disorganising process had gone on in the left knee, and a sudden attack of very acute pain on moving the joint (probably displacement of diseased cartilage) had been followed by almost absolute stiffness for the previous twelve months. The general condition had, however, improved; the hands were decidedly better, and the left wrist was stiff, but allowing the patient to nse the sewing machine; she was, however, unable to walk or stand. After a prolonged course of douche baths I endeavoured to extend the left knee under an anæsthetic. It was fixed at an angle of about $120^{\circ}$, and so firm were the adhesions that it was with great difficulty I brought it to about $150^{\circ}$ and put it up in a poroplastic splint. It is now three and a half years since the operation, and the patient has written stating that she is much better in health, that the perspirations have ceased, the hip and hands are much better, and although she still suffers occasionally from sharp pain in the left knee she can walk from half a mile to a mile.

The generalised rheumatoid arthritis of the climacteric poch which these two cases exemplify is represented by thirteen cases out of a series of sixty-five. All, of course, are females, and the average age at onset is forty-eight years, the extremes being thirty-seven and fifty-four. In many cases the disease is certainly much less severe than in our first and much larger clinical group. Intermissions of one or two years are not very uncommon after the first onset, and after a few years comparative quiesence with localisation in one or two or a few joints is much more frequent than in arthritis of the young. (See Fig. 6.)

FIG. 6.

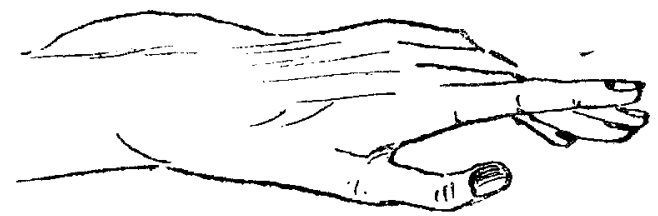

Right hand of female aged forty-nine; three years after onset of arthritis; wrist much affected.

There is at the same time less profound constitutional distarbance and thus a more favourable prognosis. In several of my cases the complaint has been almost or quite confined to the left side of the body. It is worthy of remark that this form of anthritis may be, and often is, complicated by any hereditary or other condition peculiar to the climacteric epoch in women. Thus gout in some form is not uncommon then, although entirely absent in earlier life; and more frequently there is a state of ill-health which it is difficult to name, and to which I referred at the International Medical Congress last year in these terms :- "A condition of deteriorated blood, loaded with waste prodacts, frequently met with after middle age, but more particularly in women, and due apparently to some defect of metamor phosis or excretion. There is little or no organic disease, but the patient complains, it may be, of obstinate dyspepsia, acidity, shifting rheamatism, sciatica, or lumbago; perhaps cramps, tenderness and heat in the soles of the feet or other ill-defined articular symptoms, and frequently headaches, cutaneous irritation and eczema. There is often in women a change in the symptoms after the climacteric, the articular pains and swellings becoming then more pronounced.'

In climacteric arthritis prearthritic symptoms are verg usual, such as neuralgic or shooting pains even for two or three years, burning in the soles of the feet, with or without profuse sweating, etc. In regard to the view advanced by Dr. Ord that the disease is induced by abnormal conditions or disturbance of function of the uterus or ovaries, the following notes may be added. Out of a total of forty-seven cases in women the catamenia are stated to have been irregular in five, there was fibroid tumour of the uterus in two cases, and ulceration and leucorrboea in one case. The 
pains were frequently stated to be anaffected by the catamenial period, but in two cases they were worse beforehand, in two other cases worse at the period, and in one case worse afterwards. Climacteric arthritis attacks married women mach more frequently than single, the proportion in my cases being eleven to two, and the patients are, as a rule, mothers of children. Taking all my cases together (Groups 1 and 2) in which the artbritis affected married women, $I$ find that twelve out of sixteen were mothers. In one case, that of a mother of nine children, the arthritis was said to be always better after childbirth, and in another the onset of the disease immediately followed upon childbirth. One of the severest cases of rheumatoid arthritis I have ever seen, and fatal after only four years, was that of a young married woman in whom the disease appeared twelve months after her marriage at twenty-three. The catamenia were regular and painless throughout, and there was no sign of nterine or ovarian disorder. It is worthy of remark that in many of Dr. Ord's cases the arthritis was not general, but localised, and therefore, in my view, to be clearly distinguished clinically from the disorder we have now under consideration. Farthermore, a large proportion of his cases occurred about the climacteric period, when, as Haygarth first noted in 1805, nodosities of the joints were most common. To these local and separate forms of arthricis I shall again allude.

The third variety or group is generalised rheumatoid arthritis in the old, senile rheumatoid arthritis, of which the two following cases are examples.

CASE 5.-A man aged sixty. five had been for forty years a gamekeeper on an estate situated in an exposed part of the Higblands. Coming of a healthy long-lived family he was himself a healthy man. He had never had rheamatic fever, but at fifty-one was affected with pleurisy from exposure, and since reaching the age of sixty he bad had some slight rheumatism in the right thigh. For some years past the long hours and long fasts upon the hills, with exposure and faligue, had broken his health, and the sense of duty inadequately done had preyed upon a naturally anxious and overconscientious mind. At sixty-five, therefore, he was obviously failing and depressed, bodily and mentally. At this time an acsidental fall in April or May, 1891, was followed by a sudden attaciz of acute arthritis in both hands, feet. and shoulders, with wasting, perspiration, and malaise. In July of the same year he was seized with acute pains in the arms and legs. On arrival at Strathpeffer in August the small joints of the hands and feet were swollen, tender, and paintul. He was very weak and suffered from bronchial catarrh and srasmodic cough, had a double aortic murmur, and some cedema of the legs. The urine was very acid, of specific gravity 1030, was dark with lithates, and contained a trace of albumen. In the course of $t$ wo months at Strathpeffer the articular symptoms slowly abated, but mental obscuration with delusions and much restlessness supervened, showing that the joint trouble was bat a part of a general breakdown profoundly affecting the nervous centres. He died in the spring of 1894, three years after the onset of arthritis.

CAsE 6. - A man aged seventy-four was sent to me by Di. Thom of Crieff. The patient was tall and athletic, and bad followed for many years the profession of an engiceer. With the exception that his mother had had rheumatism the tamily history was good. He was naturally of a very onergetic temperament, and in middle life had serionsly werworked himself, incurring great fatigne and mental anxiety in the management of a large navigation canal. Although often laid up for short periods from cold \&c., he had never suffered mach from rheumatism until at seventyfou: be was seizad with lambago. Loss of flesh and progressive weakness followed, with gradual involvement of many joints, especially the small joints of the hands. A few months later he was attacked by influenza, with increased debility. On arrival at Stratbpeffer in June, 1893 (eighteen months after the onset of the illness), the hands and neck presented the typical appearance of subacute arthritis, the middle pualangeal juints boing enlarged, tender, and painfal. The hands and front of the chest were much pigmented. There were much anæmia and dyspepsia and a strepicion of a systolic murmur at the base of the heart rince the above was written Dr. Thom bas been good ennugh to give me the subsequent history. Dr. Thom says "He died about a year ago-that is, rather more than two years after the commencement of the disease-of cardiac kncompetency, mainly aortic. He got rapidly feeble for two sponths before his death. He continued very dyspeptic, though he was improved by Strathpeffer. The rheumatic affection of the left hand and the back of bis neck was most marked. I do not think the rbeumatoid arthritis presented much change during the last year of his life."]

Twelve cases in all are included in this group of senile arthritis, comprising ten men and two women aged respectively fifty-nine and sixty-seven. In considering any disorder of the senile period it is of course impossible to forget that there is another age than that of years. If it be true, as Cazalis said, "L'homme a la vie de ses artères" " may we not say with equal trath, Man is as old as his nervous centres? I have placea in this group the case of a man of delicate and highly strung nervous organisation who had rheumatic fever at fifteen, but in whom there was a complete nervous and mental breakdown at forty-four, followed by severe ard intractable arthritis; also another the subject of alcoholism and erysipelas, in whose case arthritis (which I would call senile) set in after rheumatic fever at forty-five. On the average of the twelve cases the age at onset is fifty-six and a half years. In respect to etiology rhea matic fever in a debilitated subject is set down as the apparent cause in two cases; influerza in two cases; nervous or mental breakdown accomparied the artbritis in four cases out of twelve, and in one or two others there was a history of nervons symptoms in former years. This is the only for $m$ of polyarticular arthritis that can be truly said, in my opinion, to belong to the degenerative period. The arthritis of the second and third decades of life, to which find but scanty reference in the literature of the subject, belongs to the period of nervous instability. The arthritis of the climacteric epoch, or what is truly called "the change of life," is equally associated with nerrous disturbance. The incidence of insanity at these two epochs affords to $\mathrm{m}$ mind an instructive parallel. Lastly, in the aged, or rather the senile, whether from "toil or years," there is a depressed condition of nutrition in the joints, as is shown by the frequency with which localised arthritis follows trivial injuries. And in those predisposed by family tendency to such changes, degeneration and dec $3 y$ in the nerrous centres readily light up the sluggish fires of arthritis, to which senile dementia forms a parallel. Generalised or polyarticular rheumatoid arthritis is the clumsy name by which, as Dr. Archibald Garrod has done in his valuable book, cases such as those I have noted in this paper are at present separated from the localised artbritis commonly due to injury, which, however similar may be the anatomical lesion, runs an entirely different clinical course. Sir Dyce Duckworth has truly said, "Identity in the morbid anatomy does not imply identily in the processes leading up to it.'

Having now imperfectly described several clinical varieties of this disorder, some general features remain to be noted. I should say that the 65 cases of which I have full notes were all private patients and mostly persons in comfortable circumstances. Taken altcgether there are 18 men and 47 women. As respects heredity, my experierce corresponds with the results quoted by Dr. Archibald Garrcd. In 33 cases (just one-bali) there is a family history of diseases of the joints-namely, gout 9 , rhenmatoid arthritis 6 , rheumatic fever 5 , and rbeumatism 13 . Considering that family history reveals too little rather than too much, may it not be considered that a positive history of hereditary joint tronble in every second case is rather strong eviderce of a family arthritic diathesis? In 5 cases near relatives bad died from phthisis, but as I have not been much alive to the association with tubercle I think that figure may not fally represent the connexion between the two diseases. Much has been said about the connexion between rheumatoid artbritis and rhen. matism, a question which has been, as Mr. Hutchinson reminds us, made more difficult by the obscurity of the terms employed. Rheumatic fever stands apart, to my mind, as a specific infective corstitutional direase, and in my own limited experience its connexion with rheumatoid arthritis is altogether exceptional and accidental. In 65 cases there are 5 in which rheumatic fever is stated to bave immediately preceded the arihritis. One of these, however, was a mixed case (arthritis and osteomalacia). and 2 were in elderly and debilitated subjects, and therefore, as I have shown, not typical. Moreover, the diagnosis of rheumatic fever is not always quite clear, and rheumatoid arthritis is cocasionally acute and febrile in its onset. In 4 more cases an attack of rheumatic fever preceded the arthritis by a variable intervalin one case two years only, but in this case a gonorrhca was probably the cause of the arthritis. In the 3 others the 
intervals were respectively five, twenty-five, and twentynine jears. In respect to chronic rbeumatism, the connexion with arthritis appears to me to consist in the two facts that both disorders may be set up by exposure to cold and damp, and that in both there is usually a painful enlargement of the joints. At Strathceffer there are every year abundant examples of a painfal affection of the muscles, nerves, or joints, arising from exposure to cold and damp, and particularly damp soils. It affects elderly and predisposed subjects, is essentially chronic, there is never the debility or cachexia of arthritis, and in my experience arthritis has never supervened on this form of rbeumatism.

In regard to the order of onset, it appears that out of 51 cases the arthritis began in the feet in 28 and in the hands in 10. In 19 of these in which it began in the feet the disease went on by way of the hands in 13 , and by way of the knees in only 6 . My figures therefore support the statement that the invasion of the joints is usually centripetal, beginning from the small joints of the extremities.

With reference to mental disturbance in connexion with rhenmatoid arthritis it should be mentioned that, in addition to its frequent occurrerco in the senile ctses, there ara notes of two cases in the climacteric group in which partial and temporary insanity accompanied the arthritis. In arthritis of the young it is only exceptionally that one can learn the whole course of the malady, but three cases are known to me in this group which have a bearing on the point. In the first there was under my own observation a complete change in a cheerful person to morbid gloom. In the second case a girl developed arthritis at fifteen, suffered intense pain for seven years, and died from convulsive seizures at twenty. two. The third case is interesting from the patient's own observation of her mental state. I saw her first in 1885, and she had then suffered for eight years from the disease. She wrote me in February of the present year as follows: "To me the most trying turn the complaint takes is when I get in a great measure free from pain ; it goes to my head, and my brain will scarcely work at all ; my memory, too, gets very bad. So I may say I am always best and brightest when in pain." Dr. Ord has related a case in which mania came on when the arthritis subsided. There are, finally, two symptoms mentioned by $\mathrm{Dr}$. Spender and pointing to a nervons origin of the disease. Gastric crises or unprovoked vomiting I have only exceptionally met with-in four cases only. Pigmentation in the neighbourhood of the affected joints is a much commoner observation, and one of my drawings shows a rather curious pigmentation of the nails.

It was my original intention at this point to describe briefly the localised forms of artbritis to which reference bas been already made. It must suffice to say that they are, in my opinion, entirely separate from the generalised disease, and that no small confurion has arisen from confounding the two conditions under one name. I have a series of about thirty cases in which the shoulder, or hip, or knee, or one hand has been alone affected, and many in which the arthritis has been limited to the basal joint of one or both thumbs. The subjects are nearly always at or past middle age, the average age being fifty.one; and in their history, exciting causes, course, prognosis, and, above all, in the absence of constitutional symptoms, they present striking differences from arthritis in a generalised form. In the same manner I venture to separate from the latter and more serious affection numerous cases of nodi digitorum, Heberden's nodes, and lastly joint arthritis, which, in my view, are middle-age or senile changes almost always the result of hereditary gout. (See Figs. 7 to 15 , which repre-

$$
\text { FIC. } 7 .
$$

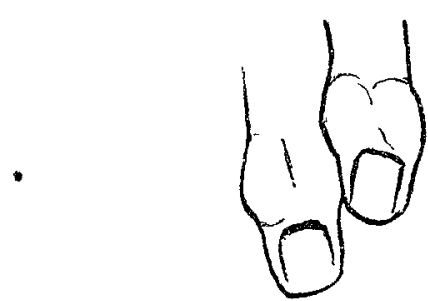

Terminal phalanges of a female about six ty years ot age (gouty).

sent joint changes in advanced life.) I have already dwelt apon the fact that in rheamatoid arthritis such changes as occur in the terminal joints usually result, not in enlargement, bat atropby.

I could wish that the clinical pictures I have endearoured to delineate were clearer and more exact in their outlines, as becomes a presentment of fact. It remains, in conclusion, to

FIG. 8.

FIG. 9.

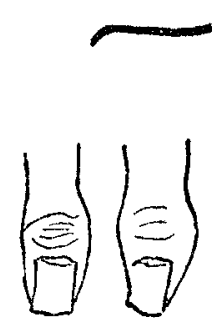

Terminal phalanges of a female aged fifty-five.

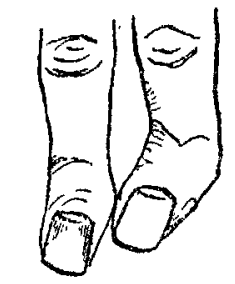

The same, aged fifty-nine.

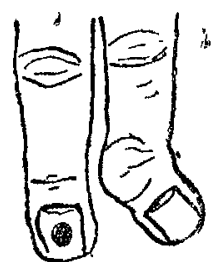

Terminal phalange of a female aged sixty-five.

ask what inferences can be properly drawn as to the true theory and pathology of rheumatoid arthritis. In the first place the causation is evidently complex, for innumerable and

Fig. 10.

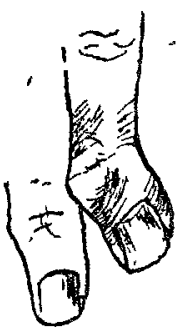

The same of a female about sixty years of age (gonty).

diverse facts testify to an inherited local valcerability both of the nervous centres and of the joints, and this shouid be placed first among the causes; next come particular con-
FIG. 12

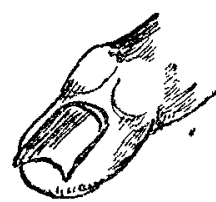

Terminal finger joint in a middle-aged female. Commencing nodes.
FIG. 11.

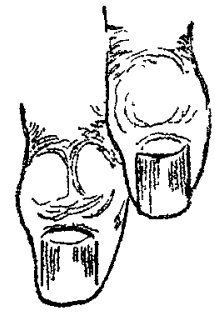

The same of another female about sixty ditions of disturbance incidental to different periods of life; then there is the depressing effect of antecedent illness; and, lastly, the external causes (cold, damp, and injury),

FIG. 14.

Fir. 15.
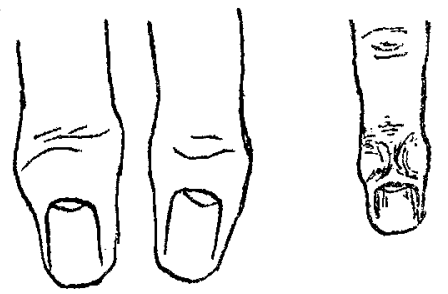

FIG. 13.

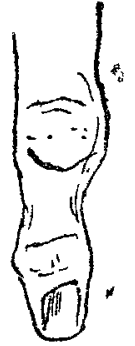

Midlle finger of a female about sixty-five years of age (a sub ect of articular gout).

Gradual painless enlargement of ter- The same in uinal finger joint a female joints aged fiftytifty-three. (Strong family tendency to "crippling ihounuatism.") seven.

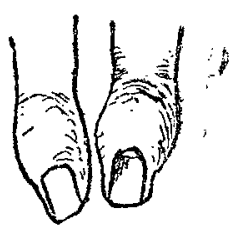

which, as we know, first, and chieffy, affect the feet and hands, in which, as a rule, arthritis hegins. To my mind there is strong evidence that some implication of the nervous systen 
takes an essential contributory part. We have gone beyond the anatomical lesion, and a disorder is found manifesting not only a general progressive affection of the joints, but other characters, to which I have referred, pointing to changes in the nervous centres. It is also found that the disorder is most frequent and most acute at the period of greatest nervous instability-namely, in young womanhood and at the climacteric epoch. In the latter case it is less severe, sometimes confined to one-half of the body and subject to intermissions analogons to the fluctuating condition of the nerrous centres at that epoch; and, moreover, in senile cases it often forms a part of a general nervous and mental breakdown, and the joint changes, according to the general character of senile disease, are less marked by inflammatory reaction than in younger life. One disease of the nervous centres is known in which organs of locomotion are affected, first by a brief inflammatory condition and then by degeneration and atrophic changes; this condition in infantile paralysis is confined to the muscles. Then again in another spinal cord affection, tabes dorsalis, we have occasionally affection of isolated joints with arthritis, in which the infammatory stage may perhaps be veiled by anæsthesia of the parts. In the present case there is a disease of the organs of locomotion in which the inflammatory period stretches over years, a disease which is frequently associated with emotional or mental disturbance and which is commonest in women, during the years when such disturbance is most common; and in this disease, according to my belief, whatever may bave been its genesis in ancestral maladies-gout, rheumatism, tubercle-yet, in the individual, nervous disturbance remains the preponderating element of causation and determines in rheumatoid arthritis a condition of neurosis almost akin to insanity, but of which the principal manifestation is found in the joints.

Strathpeffer Spa, N.B.

SOME CONSIDERATIONS ON THE CHLOROFORM QUESTION, SUGGESTED BY THE REPORTS OF THE HYDERABAD AND "THE LANCET" COMMISSIONS.

BY T. LAUDER BRUNTON, M.D., F.R.S. (Continued from $p$. ..9.)

Action of An methetios on Tissums generality. ALCOHOL, ether, and chloroform are all protoplasmic poisons. If pure alcohol be poured into a cut it will irritate the eensory nerves and burn like a red-hot iron, while it will coagulate and kill the blood, muscle, or any albuminous tissues, rendering them hard and unfit for the functions of life, and it will precipitate any soluble albuminous bodies. This can be well seen by mixing a little beef juice or albuminous urine with some pure alcohol, when the whole of the albumen will be thrown down as an insoluble precipitate. What we thus see happening in a test tube has been supposed to occur also in nerve cells, and the anæsthetic action of alcohol and its congeners has been supposed to be due to their causing a condition of semi-coagulation in the nerve cells, or at any rate such a change in the substances composing them, so as to render them sluggish and incapable of performing their functions. In the mucous membrane of the mouth we may see the same action of alcshol, for a little spirit held in the mouth will soon render the mucous membrane of the cheek white by causing superficial coagulation of its albuminous constituents. We can here notice how much stronger the action of chloroform is than that of alcohol, for it not only causes much greater irritation but much more rapid and excessive whitening, and, indeed, it causes similar whitening even on the skin.

Lodal Irbitant action of gome An masthetics.

On account of their action on albuminous substances both alcohol and chloroform have a powerful local irritant action, and if held long in the month or applied to a piece of skin denuded of epidermis will barn almost like a red-hot iron.
If alcohol be applied to the skin and its evaporation prevented by covering it with oil-silk, it will cause a feeling of burning. This is still more marked in the case of chloroform, and the burning may become so painful that it can hardly be endured. If chloroform be put on the face or its concentrated vapour be inhaled it may cause much irritation of the sensory nerves of the face, nose, and trachea, and through them affect reflexly both the heart and respiration.

ACTION ON THE NeRvous System.

Bat the vapour of all anæsthetics when inhaled in such dilution as to produce no local or reflex irritation affects the nerve centres first, and usually does so in a definite order, the highest and most complex going first and the most fundamental going last. ${ }^{1}$ Judgment and power of thought disappear first, next sensation and voluntary motion, next reflex action, then respiration and, lastly, cardiac pulsation.

ACTION of AN asthetics ON the Circulation.

If instead of putting liquid alcohol or chloroform in to the mouth the vapour only is inhaled no pain and no whitening will be indaced. We thus see that the effects of the drug upon the tissue depend very mach upon its concentration. What is true of the mouth is also true of the other tissues of the body. Alcohol, ether, or chloroform will destroy any one of them if applied to tissue in a concentrated form, but when diluted will act rather as a stimulant, and will produce no marked injury. When chloroform is in jected into the artery of a limb it will coagulate all the muscles and make the limb as etiff as a board; when injected into the heart, or when the heart is plunged into it, the muscular substance of the organ will be coagulated and its motion arrested, and if the heart of a frog be suspended in sufficiently concentrated chloroform vapour its movements will also cease; even nitrous oxide gas will kill the frog's heart if sufficiently concentrated.

\section{EFFECTS OF Dilution.}

Bat the effect is different when chloroform is inhaled, because the respiratory centre in the medulla oblongata is more readily affected by chloroform than is the heart, and, therefore, when the blood bas taken up a sufficient quantity the respiration is paralysed, while the heart continues to beat. In this respect the action of chloroform resembles that of ordinary asphyzia, whether produced by the inhalation of carbonic acid, by clogging of the bronchial tubes with mucus, by consolidation of the langs in pneumonia, or by collapse of the lung from a penetrating wound of the chest. Both clinical experience and physiological experiment conclusively prove that chloroform, as well as alcohol, ether, nitrous oxide gas, and carbonic acid, all cause death when gradually inhaled by producing paralysis of the respiration, and that a period of time, longer in some cases and shorter in others, elapses between the stoppage of the respiration and the stoppage of the heart. But long before the point of danger has been reached anæsthetics - alcohol, ether, and chloroform - lower the blood pressure. This primary and constant fall depends, at least in part, on that dilatation of bloodvessels, which leads to a glow on the skin after alcohol has been taken. It is not dangerous; on the contrary, it is rather associated with the rapid circulation and consequent stimulant effect which is so well known in the case of alcohol, and, like the fall of blood pressure produced by nitrite of amyl, may be usefal instead of injurious in the case of a feeble heart by lessening the resistance it has to overcome. Some very interesting observations on this subject were made by the late Dr. Anstie and recorded by him.

Wr. Anstie says : ${ }^{2}$ "If alcohol acts as a narcotic it lowers arterial tension, increases the frequency of the pulse, and increases the dicrotism of the curve. Here, for example, is the effect of an experimental dose of half an ounce of brandy. (Vide Figs. 1 and 2.) A healthy young man

FIG. 1.

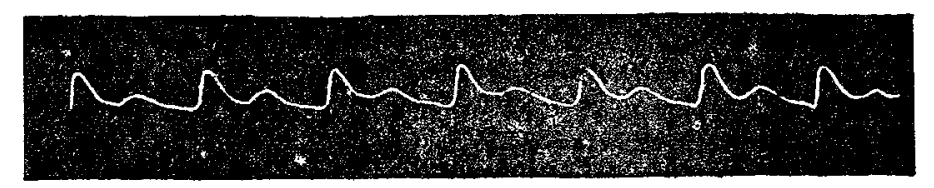

Pulse of a patient suffering from typhoid fever.

1 Hughlings Jackson: Croonian Lectures, THe LArckT, March 29th and April 12th, 1884 